This item is the archived peer-reviewed author-version of:

In objectivity we trust? Pluralism, consensus, and ideology in journalism studies

\title{
Reference:
}

Raeijmaekers Daniëlle, Maeseele Pieter.- In objectivity we trust? Pluralism, consensus, and ideology in journalism studies Journalism : theory, practice and criticism - ISSN 1464-8849 - (2015), p. 1-17

Full text (Publishers DOI): http://dx.doi.org/doi:10.1177/1464884915614244 
This paper is the final draft version of an article published in Journalism:

Raeijmaekers D. \& Maeseele P. (2015) 'In objectivity we trust? Pluralism, consensus and ideology in journalism studies', Journalism. Published online before print.

http://dx.doi.org/10.1177/1464884915614244

Please cite the published version. 


\section{In objectivity we trust? Pluralism, consensus and ideology in journalism studies}

\section{Abstract}

This paper starts from the observation that the concept of objectivity, along with its twin sentries 'balance' and 'impartiality', is generally regarded as a cornerstone of journalism and, consequently, of journalism research. The aim of this paper is to show that the analytical ideal of objectivity, instead of enabling, in fact inhibits media pluralism research. The first section focuses on unveiling the ideological nature of this ideal by relating it both socio-historically and analytically to a post-ideological and consensual understanding of society. Since we find this ideal only allowing for the evaluation of journalism within the limits of social consensus (pluralism 'within the box'), the second section seeks for alternative analytical concepts to evaluate journalism about and beyond the limits of social consensus (pluralism 'outside the box'). To illustrate the difference between both approaches, the popular concept of partisan media bias is juxtaposed to the alternative framework of de/politicization.

\section{Keywords:}

journalism studies, media pluralism, objectivity, consensus, ideology, hegemony 
If American journalism were a religion, as it has been called from time to time, its supreme deity would be 'objectivity'. The high priests of journalism worship 'objectivity' (Mindich, 1998).

As journalism has turned more professionalized over the last decades, the concept of 'objectivity' became significantly enshrined within media policies, newsroom routines and journalism education ${ }^{1}$. The general idea behind the ideal of objectivity is that if journalists depersonalize and rationalize their practices and work according to routines in line with this ideal, they end up with unbiased truth and a more or less mimetic representation of society. According to Schudson (2001: 161-162), contemporary notions of objectivity can be dated back to the 1920s, when American journalists started to see themselves as an occupational community: 'At this point [...] the objectivity norm became a fully formulated occupational ideal, part of a professional project or mission'. Moreover, it 'seemed a natural and progressive ideology for an aspiring occupational group at a moment when science was good, efficiency was cherished, and increasingly prominent elites judged partisanship a vestige of the tribal $19^{\text {th }}$ century' (Schudson, 2001: 162-163). Almost a century later, the value of objectivity is regarded as a cornerstone of journalism, and 'with no doubt the most sacred belief held among journalists worldwide' (Nordenstreng, 1995: 115). It appears in relation with journalistic aims for facts, truth and reality, which Zelizer (2004) calls the 'journalistic god-terms'. These god-terms guide journalists in dealing with a number of issues, and most importantly, in how to arrive at an unbiased, socially diverse and pluralistic public discourse. The chorus of pleas for diversity and pluralism in journalism is louder and better orchestrated than ever before, and journalists today regard both as inevitable and desirable features of modern democracy (Deuze, 2005). In that sense, the ideal of objectivity sets a number of ethical guidelines, like 'getting both sides of the story' and 'not favoring one side over the other'. These two guidelines are often operationalized into two essential components of objectivity: 'balance' and 'impartiality' (or 'neutrality'). Given the widespread use of objectivity as a journalistic guideline, it is 'not surprisingly then, academics have also adopted bias and 
objectivity as organizing concepts in many studies of journalism' (Hackett, 1984: 230). Especially regarding pluralism and diversity, objectivity has become a cornerstone of studies on journalism as well. 'Many critics of the media assume that there is a perfectly objective or fair way to represent each event in the world (Schudson, 2011: 27).' Concerned with the extent to which journalistic representations mirror social diversity and pluralism, the primary objective of studies on objectivity is to compare the features of news output with concomitant features in reality (Van Zoonen, 1994).

Contrary to these popular assumptions however, the aim of this paper is to show that the journalistic and analytical ideals of objectivity, balance and impartiality, instead of enabling, in fact inhibit media pluralism research. Drawing from a diverse and disparate literature, we will demonstrate how the ideal of objectivity not only reflects and shapes a particular assumed social consensus (on specific socio-political issues), but also incorporates a genuine belief in social consensus in itself (as an ideological ideal). In this way, this paper manifests the consequent limits of objectivity as an analytical concept ${ }^{2}$.

The first section of this paper is dedicated to unveiling the ideological nature of the ideal of objectivity. Initially, we 'zoom out' by looking at the socio-historical context in which this ideal gained prominence. In doing so, we observe a recurrent association between its popularity in media and journalism studies on the one hand and the broader belief in a post-ideological and consensual understanding of society on the other. Contrarily, the notion is found to be criticized when ideology is 'rediscovered' and social consensus is interpreted as the product of hegemony. This observation is based on an analysis which includes the end-of-ideology thesis of both the present conjuncture (starting with the fall of the Berlin Wall in 1989) and the 1950s and 1960s. Hence, the post-ideological thesis as such is found to accompany objectivity-driven journalism studies, regardless of the political project it entails (i.e. social democracy or neoliberalism).

Subsequently, we 'zoom in' by looking at the terminology of this ideal and, more specifically, its counterparts 'balance' and 'impartiality'. We argue how these concepts are grounded in an understanding of society as post-ideological and consensual, and therefore, as characterized by 
hegemony and exclusion. The second section of the paper makes the contribution of formulating an alternative vocabulary that does enable media pluralism research beyond the limits of this ideal. Since the use of objectivity as an analytical ideal only allows for journalism - and its evaluation - within the limits of social consensus (pluralism 'within the box'), it is argued how alternative analytical concepts need to allow for the evaluation of journalism about and beyond the limits of social consensus (pluralism 'outside the box'). In other words, we need to move from a conceptualization that premises social consensus to an approach that acknowledges ideological contestation. To illustrate the difference between both approaches to pluralism and to provide a clear-cut example of the latter, the popular analytical concept of partisan media bias is juxtaposed to the alternative framework of de/politicization.

Before starting our argument, it is important to emphasize that our understanding of ideology does not lean towards what Thompson (1990) has called the 'critical' conceptions (e.g. classical Marxist interpretations), but towards the more 'neutral' conceptions (e.g. post-foundationalist interpretations). The former interpret ideology in terms of a distortion of the truth, aligned with the interests of the dominant groups in society. In this case, ideology is always misleading, illusory, or onesided. We, however, find ourselves among the 'neutral' conceptions, which state that there is no such thing as absolute truth and believe that any representation of the world is always contingent. In that case, ideology is inherent to making sense of the world and to the construction of social identities in terms of 'insiders' and 'outsiders' (e.g. Howarth, 2000; Jørgensen and Phillips, 2002). Moreover, it is not only used by dominant groups in their defense of the status quo, but also necessary to subordinate groups in their struggle against the social order (Thompson, 1990). Ideological constructions only become problematic when they are no longer recognized as such, but are naturalized as taken-forgranted truths. Resultantly, they are shielded from democratic discussion and contestation.

\section{The ideological nature of objectivity}


In this first section, we aim to show how the ideal of objectivity is linked to ideological assumptions about society and media. To this end, we follow a two-fold approach. We start by zooming out and investigating the relation between the prominence of this ideal in journalism studies and specific sociohistorical shifts, before zooming in and scrutinizing its terminology. Both approaches demonstrate that the ideal of objectivity is rooted within a particular worldview.

\section{Socio-historical context: the popularity of objectivity}

Interestingly, the ideal of objectivity has been criticized most substantively in the 1970s and 1980s (Hackett, 1984; Hall et al., 1978; Hartley, 1982; van den Berg and van der Veer, 1986; Verstraeten, 1980). In that sense, it is relevant to look at the broader socio-historical context in which this ideal has either prospered or been criticized. Hall (1982: 59), for instance, was the first to interpret a shift from mainstream to critical media studies in the 1970s as part of a larger societal shift from a belief in 'the end of ideology' to the 'rediscovery of ideology'.

The end-of-ideology thesis arose in the 1950s and 1960s, with a chorus of voices in Europe and the United States (e.g. Bell, 1960; Lipset, 1960) proclaiming and celebrating the intellectual devitalization of ideology in the organization of society (Jacoby, 1999). According to Waxman (1968: 5), the theorists who supported this thesis held two basic premises: the absence of ideological politics in modern industrial society and a positive value-judgment about this reality. More specifically, they stated that the old passions of Left and Right were spent and had lost their meaning in favor of a consensus on advanced capitalism, in the appearance of the Welfare State. The following quote by one of its most well-known spokesmen illustrates how this thesis was exactly interpreted in 1960:

In the Western world, therefore, there is today a rough consensus among intellectuals on political issues: the acceptance of a Welfare State; the desirability of decentralized power; a 
system of mixed economy and of political pluralism. In that sense, too, the ideological age has ended (Bell, 1960: 99).

This post-ideological understanding of society was backed by the credentials of social science, and vice versa. With no fundamental conflicts of value left, studies of society could now fully pursue the aspiration of objectivity and being pragmatic. Scholars were found to take a positivist stance, assuming the existence of an independent reality which can be accessed through the method of scientific enquiry. They preferred 'how to' questions - questions of quantification - over value questions - the so-called 'soft' questions (Novak, 1968). According to Hall (1982: 61), such a positivist social scientific model put forward as a starting point for journalism studies the idea of media as non-ideological and their messages as empty linguistic constructs. Indeed, influenced by classic liberal theory and the idea of media as the Fourth estate, a new academic orthodoxy arose which stated that post-war news media had only very limited power (Curran, 2002). Resultantly, 'the methods of coding and processing a vast corpus of messages in an objective and empirically-verifiable way (content analysis) were vastly sophisticated and refined'. Academics focused first and foremost on manifest journalistic content. On the other hand, 'conceptually, the media message as a symbolic sign vehicle or a structured discourse, with its own internal structuration and complexity, remained theoretically wholly undeveloped' (Hall, 1982: 61).

However, the end-of-ideology thesis took a beating at the end of the 1960s, and most prominently in the 1970 s and 1980s (Jacoby, 1999). These were decades that seemed to be characterized by the proliferation of ideologies - civil rights movements, black power, feminism, etc. - under the label of a New Left. 'The existence of a "New Left" struggling with the intellectual and organizational problems of non-revolutionary radicalism indicates that ideology has not ended (Haber, 1968: 195).' Consequently, the former social consensus - on the Welfare State - was no longer treated as a reality, but as the product of hegemony (Haber, 1968; Laclau and Mouffe, 1985). 'A rosier picture was never painted. And, perhaps, neither a more misleading one (Hodges, 1967: 373).' Over the years, 
the ideological nature of the social consensus on the Welfare State was more and more recognized. Or, as Hall (1982: 63) describes it:

[Social order was no longer] expressively revealed in the spontaneous 'agreement to agree on fundamentals' of the vast majority [...]. Social order now looked like a rather different proposition. It entailed the enforcement of social, political and legal discipline. It was articulated to that what existed: to the given dispositions of class, power and authority: to the established institutions of society. This recognition radically problematized the whole notion of 'consensus'.

In these times of the 'rediscovery of ideology', the field of journalism studies changed as well. No longer were news media believed to be simply reflective mirrors of an already achieved consensus, but instead they were considered to reproduce those very definitions of the situation which favored and legitimated the existing structure of things. Resultantly, 'a whole new conception of the symbolic practices through which this process of signification was sustained intervened in the innocent garden of "content analysis"' (Hall, 1982: 64). Now, the message had to be analyzed, 'not in terms of its manifest "message", but in terms of its ideological structuration" (Hall, 1982: 64). In that sense, a positivist stance was left in favor of a constructivist approach which was oriented towards the encompassing role of ideology in fundamentally shaping news content, values and practices ${ }^{3}$ (van Dijk, 2009). Consequently, the question was no longer if social consensus was reflected, but how and why. In that sense, 'the utility of bias and objectivity as conceptual tools in the analysis of the media's ideological functioning [was] increasingly called into question' (Hacket, 1984: 230). Although the question of media objectivity continued to inspire research and debate, media scholars were increasingly drawing on terms such as 'hegemony' and 'common sense', which were reflective of the 'Gramsci boom' in social science and journalism studies (Sassoon, 1988). In sum, the media critique of the 1970s and 1980s on the concept of objectivity can be understood as part of a larger social paradigm 
shift from a 'neutral' post-ideological understanding of society to the questioning of social consensus and the rediscovery of ideology.

Interestingly, a similar social paradigm shift has taken place during the most recent decades. Since the fall of the Berlin Wall in 1989, the end-of-ideology thesis has revived (Jacoby, 1999), although this time not in the appearance of a social-democratic consensus but as a neoliberal one. For many, this event symbolized the ultimate triumph of Western capitalism over Eastern communism. For instance, it inspired Fukuyama to write his much debated article 'Have we reached the end of history?' (1989), which resulted in his (in)famous book 'The end of history and the last man' (1992). In both writings, Fukuyama claims the exhaustion of viable systematic alternatives to Western liberalism. Therefore, the fall of the Berlin Wall 'is not just the end of the Cold War [...], but the end of history as such: that is, the end point of mankind's ideological evolution and the universalization of Western liberal democracy as the final form of human government' (Fukuyama, 1989: 2). According to Fukuyama, and many other besides him, Western societies have again overcome fundamental ideological left-right conflicts and have found a new social consensus in the neoliberal project, symbolized by Margaret Thatcher's well-known 'There is no alternative'-slogan. As ideology had no more role to play, conflicts could be resolved in a rational way, either by the market or by experts. Remarkably, despite youth protest movements such as the so-called antiglobalization movement in the late 1990s, or the Occupy and Indignados-movements a decade later, the assumptions of neoliberalism have remained largely undisputed in mainstream public discourse in the West.

Nonetheless, in academia, a number of critical scholars - labeled as difference democrats (e.g. Young, 1996), radical democrats (e.g. Honig, 1993), agonistic democrats (e.g. Mouffe, 2005, 2013), etc. - have been found to identify and criticize this (neoliberal) consensus as an ideological and hegemonic practice. They claim that what is happening today is not the disappearance of ideological conflict -i.e. the arrival of public consensus - but the rationalization and moralization of conflict in liberal democratic societies. In place of a struggle between 'right and left' we are faced with a struggle between 'right and wrong', turning anyone who disagrees with the neoliberal consensus into a 
fundamentalist, traditionalist or blind radical (Mouffe, 2005). In that sense, they argue that every consensus is always at least partially the result of ideological domination and exclusion (Dahlberg, 2007).

However, within the fields of media and journalism studies, and with regard to the concept of objectivity more specifically, the recent and ongoing 'rediscovery of ideology' has not yet had a major impact. In this regard, a recent paper speculates ${ }^{4}$ about why 'ideology critique of the sort Hall advocated all but disappeared', without any signs of revival despite the present conjuncture with 'new heights of depredation in the neoliberal order' (Downey et al., 2014: 2). In line with a general continuing belief in social consensus, social science continues to adopt a positivistic scholarly paradigm, relying on notions of truth, fact and objectivity (Jones, 2013). Regarding journalism studies on pluralism, this paradigm again underlies the mainstream approach of content analysis, which is not only primarily descriptive and characterized by its supposed systematic, scientific objectivity, but also mainly concerned with paying attention to manifest content and with asking quantitative questions about how far journalistic representations mirror social actuality (Taylor and Willis, 1999).

\section{Analytical concepts: the terminology of objectivity}

The influence of a post-ideological worldview on the popularity of the ideal of objectivity has already been suggested by previous academics, like Hall. However, this paper aims to take the argument one step further by arguing how a post-ideological worldview - with a deep belief in social consensus also resides within the terminology of the objectivity norm.

Balance and impartiality are generally considered as the central components of this ideal (Entman, 1989; Hacket, 1984; Verstraeten, 1980; Westerståh, $1983^{5}$ in Carpentier, 2005). Respectively, the concepts refer to processes of selection and processes of interpretation, to what/who is covered and the character of that coverage. The balance norm refers to an equal - or inclusive, fair, harmonious - coverage of different identities and concerns in society. 'Balance requires that reports present the 
views of legitimate spokespersons of the conflicting sides in any significant dispute, and provide both sides with roughly equivalent attention (Entman, 1989: 30).' The opponent of balance, i.e. selection bias, then refers to a distorted sample of reality. For example, Lin et al. (2011: 4) state that 'regardless of a positive or negative stance towards an entity, an imbalanced quantity in coverage is itself a form of bias'. By making balance an norm for objective journalistic coverage, the underlying assumption then is that society - as ultimate benchmark for a mimetic media representation - is balanced as well. A society that is relatively equal and harmonious is exactly the sort of society that the post-ideological thesis proclaims: '[it] represents society as if there are no major cultural or economic breaks, no major conflicts of interests between classes and groups; whatever disagreements exist, it is said, there are legitimate and institutionalized means for expressing and reconciling them' (Hall et al., 1978: 55). Thus, it is believed that although society is characterized by competition and conflict, a harmonious society is possible because all parties are considered to be reasonable. The balance norm aims for this reasonable harmony and therefore relates to a broader basic framework of agreement or consensus. Indeed, '[t]he bread and butter of news is conflict, violence, rivalry and disagreement. But for all these negatives to be newsworthy, a prior assumption of the "underlying" consensus to which they are a threat must be at work' (Hartley, 1982: 83). In other words, while the bread and butter of news might be conflict, its basic ingredient is consensus. In sum, by starting from a representation of society as if there are no major insurmountable conflicts of interest, the notion of balance premises a relatively harmonious and consensual society.

Second, the notion of impartiality refers to a detached or factual dealing with contrasting claims, frames, interpretations and problem definitions. This means that journalists refrain from ideological or emotional judgement or value-laden reporting, and only use facts and rational arguments to build their story (Entman, 1989; Schudson, 2001). It is contrasted with the notion of presentation bias, which refers to a distorted view of reality. For example, Gentzkow and Shapiro (2006: 281) argue that in essence every news article is based on the same set of underlying facts, 'yet by selective omission, choice of words, and varying credibility ascribed to the primary source, each 
conveys a radically different impression of what actually happened'. Again, such an idealization of impartial journalistic coverage reflects a post-ideological view of society, in which detached procedures and rational debate are essential for social consensus. For people to agree upon social decisions, they have to move beyond passions and emotions. Either conflicting interests and values are reconciled by experts through technical knowledge and impartial procedures (Beck, 1992; Giddens, 1994), or by citizens who engage in rational debate over common problems, resulting in a critically informed public opinion that can guide decision-makers in reaching consensus (Benhabib, 1996; Habermas, 1996). Such post-ideological ideals of resolving conflicts in a rational way reside within the ideal functioning of news media and the benchmark of neutral coverage. Journalism - as 'mirror' of social debate or as 'public forum' for social debate - is expected to adapt to this kind of impartial discourse in order to allow for further social consensus. In sum, the concepts of balance and impartiality clearly reflect the condition of a relative social equality between individuals and groups (and between and within regions), which implies that roughly similar material and immaterial opportunities and means are enjoyed by each and every individual.

However, critical media scholars, both in the 1970s-1980s and more recently, have pointed at the ideological implications of blindly adopting the concepts of objectivity (e.g. Carpentier and Cammaerts, 2006; Dahlberg, 2005, 2007a; Hackett, 1984; Hall et al., 1978; Hartley, 1982; Taylor and Willis, 1999; van den Berg and van der Veer, 1986; Verstraeten, 1980). First, these authors argue how the consensual logic of balance and impartiality is applied in a context of power asymmetries and structural inequalities, which is hardly ever adequately recognized by journalists and scholars who use the concepts. Second, these latter also neglect the fact that all framing of meaning - including what it means to be objective, balanced, or impartial - necessarily creates and reproduce exclusion.

As a discourse, both social scientists and journalists aren't just directing inquires. They ontologically define what constitutes the objects of study (and what doesn't), how these 
objects will be studied (and how not), what it means to know them (or not), and what will be seen as valuable (and what will not) (Jones, 2013: 6).

Balance and impartiality cannot be regarded as 'neutral' or 'universal' concepts, since they are interpreted in terms of an assumed consensus about which identities and concerns are relevant or acceptable to the public interest. These norms imply a construction of the news in terms of dominant groups and beliefs, excluding those that are 'outside' the established social consensus.

In other words, it involves a struggle for cultural domination, for hegemony. This struggle leads to a differentiation between the dominant discourses that achieve authoritative status and subordinate discourses that are marginalized or even silenced [...]. So consensus over the boundaries of discourse, and any consensus resulting from deliberations within these boundaries, is always intertwined with asymmetrical power relations and a struggle for domination (Dalhberg, 2007a: 835).

In that sense, balance and impartiality, as counterparts of the widely adopted notion of objectivity, create and reproduce particular inside/outside assumptions: the former regarding which identities and concerns are legitimate/illegitimate to participate in social debates, the latter regarding which forms of communication are legitimate/illegitimate to persuade others of those positions. Indeed, the balance norm refers to giving space to various sides of a debate as long as they are reasonable. Inevitably, the identification of 'reasonable' positions also implies the identification of 'extreme' positions. 'Groups outside the consensus are seen as deviant and marginal, be they skinheads or strikers (Hartley, 1982: 83).' However, this naming of one position as 'irrational' or 'extreme', and another as 'reasonable' or 'neutral' is highly ideological in that it promotes the status quo definition of what is irrational or extreme and what is reasonable and neutral (Dahlberg, 2007b). Similarly, the impartiality norm favors a particular 'legitimate' form of communication, namely 'one that encourages 
representational accuracy, logical coherence, and a dispassionate contestation of opinion (Dahlberg, 2005: 113)'. In essence, this comes down to Western high-culture masculine communication (Young, 1996). Consequently, participants whose naturalized modes of communication are closer to what is deemed legitimate will be advantaged over those who hold other styles of communication, the socalled tittle-tattle in the margins or passionate individual expressions without much value (Dahlberg, 2007a; Cammaerts, 2009). 'The reasonableness can be used to exclude the "irrational" (for example, "emotional" women or the "loony left"), producing a "reason-based" debate that reaches conclusions that are conveniently congenial to "civilized" people (Curran, 2002: 237).' In that way, a frontier is drawn between legitimate and illegitimate forms of discourse, thereby excluding particular worldviews. So, also the impartiality norm is considered to be highly ideological.

In conclusion, the terminology of objectivity both reflects and shapes an assumed social consensus. Or as Fowler (1991: 222) expresses it: 'from a broader perspective, [news] reflects, and in return shapes, the prevailing values of a society in a particular historical context'.

\section{Towards an alternative analytical vocabulary}

By now, we have demonstrated that the notion of objectivity is rooted within a paradigm of social consensus, both socio-historically and analytically. Thus, the analysis of news media is taking place within a broader basic framework of consensus and within the conventional understandings ${ }^{6}$ of society. 'It is not the vast pluralistic range of voices which the media are sometimes held to represent, but a range within certain distinct ideological limits (Hall et al., 1978: 59).' In that sense, we can state that the ideal of objectivity only allows for evaluating pluralism 'within the box', i.e. within the limits of existing social consensus. We start this paragraph by illustrating this using the popular concept of partisan media bias. Subsequently, we begin with a search for alternative analytical concepts that allow to evaluate journalism about and beyond the limits of social consensus (i.e. pluralism 'outside the box'). Since this implies moving from a conceptualization that premises social consensus to an approach that 
acknowledges ideological contestation, both in terms of its scope and form, the framework of de/politicization is put forward as a potential alternative.

\section{From pluralism 'within the box'...}

Although journalism research these days primarily starts from a post-ideological understanding of society, the notion of ideology is not absent in positivist empirical studies. Mostly, it is analyzed as 'ideological bias' or 'partisan bias', since '[i]t is partisan bias in the news which has attracted the most public interest and attention' (D'Alessio and Allen, 2000: 134). The partisan media bias-approach is characterized by quantitative content analyses into the extent of unbalanced and partisan political coverage, which is operationalized as the varying levels of attention for specific politicians, political parties or policy positions in specific news outlets (Groeling, 2013; Groseclose and Milyo, 2005). However, such an approach allows media researchers to only gain insights about pluralism 'within the box'. To start with, the partisan bias-approach adopts a limited understanding of 'ideology': it explicitly focuses on politicians, political parties, and exclusively politically-driven issues, i.e. the field of institutional politics. Quite revealing in this regard is the following motivation by D'Alessio and Allen (2000: 134) in a paper reporting on a meta-analysis of studies on partisan media bias: 'Unlike opinions on the nature of the economy, where it would appear that there is a large preference among Americans for capitalism rather than communism, opinions on political matters are widely divergent'. Not only does this imply that the economy is excluded as a 'political matter', but also that the benchmark for evaluating the level of ideological pluralism in news coverage is dependent on the ideological divergence between political parties. Moreover, this latter category is generally restricted to those parties with most parliamentary seats. For example, in American studies on partisan media bias, the classic aim that news media should strictly reflect the outcome of social consensus can be found in the implicit or explicit definition of fair coverage as the equal treatment of Republicans and Democrats, which comes down to a 50/50 coverage or a coverage that is in line with the number of 
seats each party possesses. 'Although no one expects there to be no biased statements in $100 \%$ of reports, a 50-50 breakdown of them would be indicative of a deliberate attempt to achieve balance, and thus deviations from the 50-50 pattern would arguably be an indication of bias of some kind (Groeling, 2013: 143).' Clearly, the notion of partisan bias is rooted within a framework of objectivity and social consensus: pluralism is not interpreted as a matter of conflicting values, norms and political preferences vis-à-vis a given social and political order, but about the disagreements which are allowed within that given social and political order. Or, to put it simply: about those issues that Democrats and Republicans choose to disagree about. In other words, since the analytical concept of partisan media bias excludes those matters where there is ideological convergence between both parties (say, global neoliberal capitalism and American imperialism), it only allows for evaluating pluralism 'within the box', i.e. within the limits of existing social consensus. In the end, such an approach to media pluralism does not appropriately take into account the democratic role of news media (definitely not in times of global economic and geopolitical crisis, like we are experiencing since the start of the financialeconomic crisis in 2008). It does not allow for a genuine democratic debate amongst citizens as ideological issues are monopolized by politics and political parties, and framed within the status quo. Therefore, it is imperative to evaluate the level of media debate using a conceptual framework that allows for pluralism 'outside the box'.

\section{...to pluralism 'outside the box'}

The objectivity benchmark should not only be challenged because of the ideological limits it sets, but foremost because of the fact that these limits are not perceived as such. Rules of objectivity reflect and shape an assumed social consensus about a hegemonic ideological project, while simultaneously disguising or camouflaging its ideological character. This is most problematic since ideology is at its strongest when it is no longer defined and perceived as such, when its assumptions and preferences appear evident and logical, i.e. hegemonic or depoliticized (Atton, 2002; self-reference, 2013). 
Therefore, 'no longer objectivity can be taken as the opposite of ideology in the media, if indeed the forms and rhetoric of objectivity help to reproduce dominant political frameworks' (Hackett, 1984: 253). In that sense, we are urgently in need of news analysis about and beyond the limits of objectivity and social consensus, i.e. for pluralism 'outside the box'. Clearly, such a shift in journalism studies requires breaking with traditional assumptions and approaches. As Downey et al. (2014: 6) argue: '[...] if ideology critique is going to have any purchase, if it is to change hearts and minds in the field, then a more fully worked-out theoretical and methodological approach will be necessary'. Therefore, we choose to make this exercise both regarding specific assumptions about society (normative assumptions) and how these are operationalized towards journalism (analytical concepts).

First, regarding normative assumptions, we have shown that the notion of media objectivity is rooted within a belief in ideological harmony - 'the end of ideology' - and the ideal of social consensus. However, such an understanding of society does not recognize the irrefutable presence of the ideological limits to a consensus, and more specifically, the involved mechanisms of exclusion: 'There is always an "outside" to discourse, a set of meanings, practices, identities and social relations, which is defined by exclusion and against which discursive boundaries are drawn' (Dahlberg, 2007a: 835). Obviously, the recognition of such an 'outside' is essential to arrive at and evaluate pluralism 'outside the box'. If we accept that society is inevitably marked by conflict and asymmetries of power and that every social order is the result of hegemonic practices, dominance and exclusion, then this implies that we need to start from a framework with ideological hegemony (instead of harmony) and contestation (instead of consensus) as basic concepts. Following such an interpretation, consensus is perceived as the temporary result of a provisional hegemony, which, from a perspective of pluralist democratic politics, is - and must be - continuously questioned (Mouffe, 2005). Contestation ${ }^{7}$, on the other hand, refers to how we can only speak of pluralism when there is a confrontation between clearly differentiated ideological positions.

Second, regarding analytical concepts, it is necessary to replace the widely adopted benchmark of objectivity with the identification of ideology in order to reflect on media pluralism 'outside the 
box'. 'In any theory which seeks to explain both the monopoly of power and the diffusion of consent, the question of the place and role of ideology becomes absolutely pivotal (Hall, 1982: 86).' Journalism should not be evaluated on the extent it leaves out - thus, camouflages - ideological positions, but on the extent to which it makes these ideological positions explicit. 'It is important for audiences to be shown that there are different views; people should not be told "this is the correct interpretation"; there are always different interpretations (Mouffe in Carpentier and Cammaerts, 2006: 973).' Therefore, the notion of objectivity and its counterparts 'balance' and 'impartiality' should be reconsidered in favor of a terminology that benchmarks ideological contestation. Indeed, to change dominant modes of thinking, we are in need of an alternative analytical vocabulary: a new language outside the confines of the old paradigm is precisely the way to break boundaries and shape new understandings (Jones, 2013).

Only a small number of scholars have recently been found to start from the concepts of ideology and contestation in their analysis of pluralism in news reporting, regarding both the range of positions in media debates and particular modes of communication (e.g. Dahlberg, 2005, 2007a; Phelan, 2007). Although these studies provide valuable theoretical insights, they often lack a systematic methodological framework for news research. To encourage a genuine shift in journalism research to pluralism 'outside the box', we put forward our recent work on de/politicization as a welldeveloped analytical tool for investigating news discourse ${ }^{8}$ (self-reference, 2014; self-reference, 2015). In its attempt to rethink the evaluation of journalistic practices to account for whether these are found to either encourage or impede a broad democratic and pluralist debate on specific social issues, this work focuses on ideological contestation in news coverage, both in terms of its scope and form. On the one hand, a concern about the scope of ideological contestation critically questions the balance norm, as it makes clear that what is at stake is the confrontation of differentiated ideological positions (or the absence of it). For each respective social issue, this requires the identification of the range of positions with regards to the relevant ideological conflicts that underlie the issue. Hence, the concept of ideological 'fault lines' is introduced as a heuristic tool, representing a struggle between competing 
analyses about what constitutes progress with regards to specific political-ideological categories (Carvalho, 2007). For instance, in their work on genetically modified food, the relevant two fault lines concerned the techno-environmental (i.e. the role of science and technology in nature and society) and economic fault line (i.e. the role of the market in society). In their work on the Belgian government formation, the latter fault line was found relevant in addition to the ethnic-linguistic fault line (i.e. the relationship between regional and federal levels of government). On the other hand, a concern about the form and articulation of contestation critically questions the impartiality norm. By focusing on which specific ideological preferences are either politicized or depoliticized, this framework acknowledges and allows to reveal the strategies of in- and exclusion at work. Processes of depoliticization are qualified as impeding democratic-ideological debate, since these refer to discursive strategies which distinguish legitimate from illegitimate actors and demands, based on the assumption of an existing moral or rational consensus. Instead of considering 'rational' or 'moral' argumentation as a neutral - and therefore the only legitimate - mode of communication, it is understood as a particular discursive strategy to shift the site of struggle from ideological contestation between alternative futures to a struggle between 'rational' and 'irrational' (mostly interpreted as 'scientific' and 'unscientific', or 'economic' and 'uneconomic') or between 'good' and 'evil'. This is qualified as impeding democratic debate since it stigmatizes certain actors and demands as enemies of an existing consensus and, in so doing, acts in the service of concealing rather than revealing what is stake. On the other hand, processes of politicization are qualified as encouraging democratic-ideological debate. Instead of amplifying a moral or rational consensus, these refer to discursive strategies which reveal conflicting assumptions, values and interests underlying conflicting positions. Relating these to alternative worldviews creates the discursive space for a broad, pluralist democratic debate between these worldviews, and as a result, about and beyond the limits of social consensus, thus, for pluralism 'outside the box'. Politicization then refers to a logic of contestation, while depoliticization refers to a logic of consensus. Regarding the analyses of news coverage on (i) genetically modified food and (ii) the Belgian government formation, democratic-ideological debate was found to be restricted or even 
absent in mainstream, commercialized newspapers: the outlets predominantly made use of depoliticizing discursive strategies to present particular projects and reforms as inevitable and natural developments.

Despite these examples, there is still an urgent need for further theorization and empirical testing of this 'outside the box'-framework. As Hall already mentioned in the 1980s, 'the critical paradigm is by no means fully developed; nor is it in all respects theoretically secure. Extensive empirical work is required to demonstrate the adequacy of its explanatory terms, and to refine, elaborate and develop its infant insights' (1982: 88). Remarkably, not much has changed in the last three decades, despite the enormous democratic challenges of our times, not in the least the financialeconomic crisis and its ramifications since 2008 and the events in the Arab World. In this regard, we sincerely hope this paper serves as a wake-up call.

\section{End notes}

${ }^{1}$ Compared to Europe, the ideal of objectivity has traditionally been more explicitly articulated within American journalism. According to Schudson (2011: 78), "'objectivity” as a professional value in American journalism was already occupied in Europe by a self-understanding among journalists that they were high literary creators and cosmopolitan political thinkers'. So, although more implicitly, the objectivity norm can also be considered to be a cornerstone of European journalism - and of other journalistic cultures (e.g. Hafez 2002). Furthermore, the ideal of objectivity has been instituted differently in press and broadcasting: whereas it has gradually become the norm in press coverage through changes in the professional culture of journalists, it was rather quickly turned into a legal obligation for broadcasting services (Curran, 2002). 
${ }^{2}$ The objectivity norm has been criticized many times before. Both Carpentier and Trioen (2010) and Skovsgaard et al. (2013) state these critical discourses differ on two levels. First, on a normative level, the attack on the objectivity norm is triple flanked: on one flank journalists are blamed for not meeting the requirements of the objectivity norm, on the second flank critics write off objectivity as an illusion, and on the third flank the objectivity norm is considered to be undesirable (Skovsgaard et al., 2013). Similarly, Carpentier and Trioen (2010) refer to Lichtenberg (2005) to distinguish three different claims regarding journalistic objectivity: 'journalism isn't objective', 'journalism cannot be objective', and 'journalism shouldn't be objective'. This paper can be situated within the third category. Second, on a conceptual level, a difference should be made between objectivity as a moral ideal, and objectivity as a pragmatic and practical tool (Skovsgaard et al., 2013). In other words, between objectivity as a norm within journalistic ideology, and objectivity as embedded in journalistic practices (Carpentier and Trioen, 2010). This paper focuses on the former.

${ }^{3}$ Here, it is crucial to state that not all constructivist research has a critical orientation. For example, within media framing research, the analytical concept of frames might be reduced to mere story topics, attributes, or issue positions. In that case, scholars do not pay attention and/or question the ideological origin and implications of frames (self-reference, 2010).

${ }^{4}$ Following Duggan (2003), the authors interpret the lack of ideology critique as a consequence of a general retreat of left-wing perspectives in academia. They see this political retrenchment accommodated in academic research through the rise and current predominance of a type of identitybased politics which negates questions about capitalism and economic inequality (Downey et al., 2014).

${ }^{5}$ Actually, Westerståhl (1983) has identified six components of objectivity: he distinguishes two basic dimensions of objectivity: factuality and impartiality. Both consist of two components. Factuality's 
components are relevance and truth(fulness) and impartiality's components are balance and neutrality. However, we choose to focus on 'balance' and 'neutrality' (renamed as 'impartiality') because these are recurring concepts in both traditional and critical literature on media objectivity and pluralism.

${ }^{6}$ Dahlberg formulates this as follows: 'Certainly, bringing difference together through the mass media may promote social stability. However, these media support social stability not because they provide for democratic debate but because, as shown by decades of critical media research, they draw societal voices into largely homogeneous communicative spaces bound by dominant discourse' (Dahlberg, 2007a: 840).

7 However, inevitably, we are faced with questions such as is there not a point at which healthy diversity turns into unhealthy dissonance?' (McLennan, 1995 in Karppinen, 2007: 12). Certainly, not all viewpoints should be respected, specifically those that refuse to accept the existence of other differences and the pluralization of lifestyles (Dahlberg, 2007: 833). In line with this thinking, Mouffe $(2005,2013)$ introduces the notion of 'conflictual consensus'. She acknowledges that dissensus is with no doubt necessary, but it must always be accompanied by a certain level of consensus. Consensus is needed on the 'ethico-political' values that are at the basis of liberal democracy and its constitutive institutions - like liberty, equality, and fraternity - but there will always be disagreement concerning the meaning of these values and the way they should be implemented (Mouffe, 2013: 8).

8 It concerns a 'multiperspectival approach' (Jørgensen and Phillips, 2002), combining elements of both discourse theory (DT) and critical discourse analysis (CDA). Although we share DT's politicalphilosophical framework on the role of ideology, conflict and democracy in society (e.g. Mouffe), we lean more towards CDA's view on discourse and social construction. In general, DT holds a rather radical form of social constructivism: it rejects any distinction between linguistic and material 
practices, and emphasizes how phenomena or objects can only acquire meaning within a discourse (Carpentier and Cammaerts, 2006; Phelan and Dahlberg, 2011). Thus, it sees all social reality as discursive. CDA, on the other hand, understands semiotic practices such as language and images as different from - but dialectically related to - other social practices (Phelan and Dahlberg, 2011; Wodak and Meyer, 2009). Consequently, it believes that discourses not only (re-)shape social relations and events, but are also shaped by society. Such a mild form of social constructivism explicitly acknowledges the social/political/cultural context in which discourses operate. In that sense, CDA's discursive approach perfectly fits our analytical framework, as we aim to reveal how news coverage simultaneously reflects and constructs (an assumed consensus about) a particular social order.

\section{References}

Atton C (2002) News Cultures and New Social Movements: radical journalism and the mainstream media. Journalism Studies 3(4): 491-505.

Beck U (1992) Risk society: Towards a new modernity. London: Sage Publications

Bell D (1960) The End of Ideology in the West. In: Waxman Cl (ed) (1968) The End of Ideology Debate. New York: Funk \& Wagnalls, pp. 87-105.

Benhabib S (ed) (1996) Democracy and difference. Princeton: Princeton University Press.

Cammaerts B (2009) Radical pluralism and free speech in online public spaces: The case of North Belgian extreme right discourses. International journal of cultural studies 12(6): 555-575.

Carpentier N (2005) Identity, contingency and rigidity: The (counter-) hegemonic constructions of the identity of the media professional. Journalism 6(2): 199-219. 
Carpentier N and Cammaerts B (2006) Hegemony, democracy, agonism and journalism: An interview with Chantal Mouffe. Journalism Studies 7(6): 964-975.

Carpentier N and Trioen M (2010) The particularity of objectivity: A post-structuralist and psychoanalytical reading of the gap between objectivity-as-a-value and objectivity-as-apractice in the 2003 Iraqi War coverage. Journalism 11(3): 311-328.

Carvalho A (2007) Ideological cultures and media discourses on scientific knowledge: re-reading news on climate change. Public Understanding of Science 16(2): 223-243.

Curran J (2002) Media and power. London: Routledge.

D’Alessio D and Allen M (2000) Media bias in presidential elections: a meta-analysis. Journal of Communication 50(4): 133-156.

Dahlberg L (2005) The Habermasian public sphere: Taking difference seriously?. Theory and Society 34(2): 111-136.

Dahlberg L (2007a) Rethinking the fragmentation of the cyberpublic: from consensus to contestation. New media \& society 9(5): 827-847.

Dahlberg $L$ (2007b) The internet and discursive exclusion: from deliberative to agonistic public sphere theory. In: Dahlberg L and Siapera E (eds) Radical democracy and the internet: Interrogating theory and practice. New York: Palgrave Macmillan, pp. 128-147.

Deuze M (2005) What is journalism?: Professional identity and ideology of journalists reconsidered. Journalism 6(4): 442-464.

Downey J, Titley G and Toynbee J (2014) Ideology critique: the challenge for media studies. Media, Culture \& Society 36(6): 878-887.

Entman R (1989) Democracy without citizens. Oxford: Oxford University Press.

Fowler R (1991) Language in the news: Discourse and ideology in the press. London: Routledge.

Fukuyama F (1989) Have We Reached the End of History?. Santa Monica: Rand Corporation.

Fukuyama F (1992) The end of history and the last man. New York: Simon and Schuster. 
Gentzkow M and Shapiro JM (2010) What drives media slant? Evidence from US daily newspapers. Econometrica 78(1): 35-71.

Giddens A (1994) Beyond left and right: The future of radical politics. Oxford: Polity.

Groeling T (2013) Media bias by the numbers: Challenges and opportunities in the empirical study of partisan news. Annual Review of Political Science 16: 129-151.

Groseclose T and Milyo J (2005) A measure of media bias. The Quarterly Journal of Economics 120(4): 1191-1237.

Haber RA (1968) The End of Ideology as Ideology. In: Waxman Cl (ed) (1968) The End of Ideology Debate. New York: Funk \& Wagnalls, pp. 182-205.

Habermas J (1996) Between facts and norms (trans. Rehg W). Cambridge: The MIT Press.

Hackett RA (1984) Decline of a paradigm? Bias and objectivity in news media studies. Critical Studies in Media Communication 1(3): 229-259.

Hafez K (2002) Journalism Ethics Revisited: A Comparison of Ethics Codes in Europe, North Africa, the Middle East, and Muslim Asia. Political Communication 19(2): 225-250.

Hall S (1982) The rediscovery of ideology: Return of the repressed in media studies. In: Gurevitch M, Bennett T, Curran J and Woollacott J (eds) Culture, society and the media. London: Methuen, pp. 56-90.

Hall S, Critcher C, Jefferson T, Clarke J and Roberts B (1978) Policing the crisis: Mugging, the state and law and order. London: The Macmillan Press Ltd.

Hartley J (1982) Understanding news. London: Methuen \& Co.

Hodges DC (1967) The End of 'The End of Ideology'. In: Waxman Cl (ed) (1968) The End of Ideology Debate. New York: Funk \& Wagnalls, pp. 373-388.

Honig B (1993) Political theory and the displacement of politics. New York: Cornell University Press. Howarth D (2000) Discourse. Maidenhead: Open University Press. Jacoby R (1999) The end of utopia: Politics and culture in an age of apathy. New York: Basic Books. 
Jones JP (2013) Toward a New Vocabulary for Political Communication Research. International Journal of Communication 7: 510-530.

Jørgensen M and Phillips L (2002). Discourse analysis as theory and method. London: Sage.

Karppinen K (2007) Making a difference to media pluralism: A critique of the pluralistic consensus in European media policy. In: Cammaerts B and Carpentier N (eds) Reclaiming the media: Communication rights and democratic media roles. Bristol: Intellect Books, pp. 9-30.

Laclau E and Mouffe C (1985) Hegemony and socialist strategy: Towards a radical democratic politics. London: Verso.

Lin YR, Bagrow JP and Lazer D (2011) More Voices Than Ever? Quantifying Media Bias in Networks. ICWSM 1(arXiv: 1111.1227): 1-10.

Lipset SM (1960) The End of Ideology?. In: Waxman Cl (ed) (1968) The End of Ideology Debate. New York: Funk \& Wagnalls, pp. 69-86.

Mindich DT (1998) Just the facts: How objectivity came to define American journalism. New York: New York University Press.

Mouffe C (2005) On the political. London: Routledge.

Mouffe C (2013) Agonistics: Thinking the world politically. London: Verso.

Nordenstreng K (1995) The journalist: A walking paradox. In: Lee P (ed) The democratization of communication. Cardiff: University of Wales Press, pp. 114-129.

Novak M (1968) An End of Ideology. In: Waxman Cl (ed) (1968) The End of Ideology Debate. New York: Funk \& Wagnalls, pp. 389-397.

Phelan S (2007) The discursive dynamics of neo-liberal consensus: Irish broadsheet editorials and the privatization of Eircom. Journal of Language and Politics 6(1): 7-28.

Phelan S and Dahlberg L (2011) Discourse theory and critical media politics: An introduction. In: Dahlberg L and Phelan S (eds) (2011) Discourse theory and critical media politics. London: Palgrave Macmillan. 
Sassoon AS (1988) The Gramsci Boom Continues. History Workshop Journal 26(1). Oxford: Oxford University Press, pp. 213-214.

Schudson M (2001) The objectivity norm in American journalism*. Journalism 2(2): 149-170.

Schudson M (2011) The sociology of the news, Second edition. New York: W.W. Norton \& Company, Inc.

Skovsgaard M, Albæk E, Bro P and de Vreese C (2013) A reality check: How journalists' role perceptions impact their implementation of the objectivity norm. Journalism. Published online: 1464884912442286.

Taylor L and Willis A (1999) Media studies: Texts, institutions and audiences. Oxford: Blackwell Publishers Ltd.

Thompson JB (1990) Ideology and modern culture: critical social theory in the era of mass communication. Cambridge: Polity Press.

van den Berg H and van der Veer CG (1986) Ideologie en massamedia. Amsterdam: VU Boekhandel.

van Dijk TA (2009) News, Discourse, and Ideology. In: Wahl-Jorgensen K and Hanitzsch T (eds) (2009) The handbook of journalism studies. London: Routlegde.

van Zoonen L (1994) Feminist media studies (Vol. 9). London: Sage.

Verstraeten H (1980) Pers en macht: een dossier over de geschreven pers in België. Leuven: Kritak.

Waxman Cl (1968) Introduction. In: Waxman Cl (ed) (1968) The End of Ideology Debate. New York: Funk \& Wagnalls, pp. 3-9.

Wodak R and Meyer M (2009) Methods of Critical discourse analysis. Second edition. Los Angeles: Sage. Young IM (1996) Communication and the other: Beyond deliberative democracy. In: Benhabib, S. (ed) Democracy and difference: Contesting the boundaries of the political (Vol. 31). Princeton, NJ: Princeton University Press, pp. 120-135.

Zelizer B (2004) When facts, truth, and reality are God-terms: on journalism's uneasy place in cultural studies. Communication and Critical/Cultural Studies 1(1): 100-119. 
[3 self-references] 